\title{
RESECTION OF THE ATRIAL APPENDAGES AND ITS IMPACT IN THE NATRIURETIC HOMEOSTASIS: DEVELOPMENT AND VALIDATION OF AN ANIMAL MODEL IN AN ACADEMIC MEDICAL CENTER
}

\author{
Ricardo Marquez-Velasco ${ }^{1,2}$, Maite Vallejo ${ }^{3}$, Jorge M. Catrip-Torres ${ }^{4}$, María del Carmen \\ Lespron-Robles $^{5}$, JuAN Villegas-JUaChe ${ }^{6}$, Francisco J. Molina-MendeZ ${ }^{5}$, Luis M. AmezCUA-Guerra ${ }^{1,7}$, \\ Jesús VARgAS-BARRON ${ }^{8}$, AND GHEORGHE POP ${ }^{9 *}$ \\ ${ }^{1}$ Department of Immunology, Instituto Nacional de Cardiología "Ignacio Chávez" (INCICH), Mexico City; \\ ${ }^{2}$ Department of El Hombre y su Ambiente, Universidad Autónoma Metropolitana (UAM)-Xochimilco, Mexico City; \\ Departments of ${ }^{3}$ Sociomedical Research; ${ }^{4}$ Surgery; ${ }^{5}$ Anesthesiology; and ${ }^{6}$ Central Animal Facility, INCICH, Mexico City; \\ ${ }^{7}$ Department of Health Care, UAM-Xochimilco, Mexico City, Mexico; ${ }^{8}$ Research Division, INCICH, Mexico City, Mexico; \\ ${ }^{9}$ Department of Cardiology, Radboud University Medical Center Nijmegen, The Netherlands
}

\begin{abstract}
Background: The left atrial appendage (LAAp) resection is an effective treatment approach to reduce the risk of thromboembolism in patients with atrial fibrillation. Objective: To study was to study the impact of removing atrial appendages in the production of natriuretic peptides (NPs) in conditions of volume overload and to develop an experimental model of LAAp resection. Materials and Methods: In a swine model of ischemic heart failure (HF), serum NP levels were measured before (Basal-1A) and after (Basal-1B) a fluid overload. Animals were grouped as follows: (0) preserved appendages, (1) resected LAAp, and (2) both atrial appendages resected. Levels of NP were measured before (2A) and after a fluid overload (2B). Results: Furin levels were higher in Group 0-2A than in Group 2-2A, and a significant increase was found in Group 0-2B compared to Groups 1-2B and 2-2B. Corin levels increased in Basal-1B versus Basal-1A. Atrial NP (ANP) decreased in Basal-1B compared to Basal-1A. After HF induction, ANP increased in Groups 2-2A and 2-2B. Conclusions: Resection of atrial appendages drastically modifies the natriuretic mechanisms of cardiac homeostasis, especially after a fluid overload challenge. Herein, we describe the face and predictive validation of an animal model of atrial appendage resection useful to investigations in translational medicine. (REV INVEST CLIN. 2020;72(2):103-9)
\end{abstract}

Key words: Atrial fibrillation. Heart failure. Natriuretic peptides. Atrial appendage resection.

*Corresponding author:

Gheorghe Pop

E-mail: gheorghe.pop@radboudumc.nl
Received for publication: 3-06-2019

Approved for publication: 16-07-2019

DOI: $10.24875 / R I C .19003132$

0034-8376 / (c) 2019 Revista de Investigación Clínica. Published by Permanyer. This is an open access article under the CC BY-NC-ND license (http://creativecommons.org/licenses/by-nc-nd/4.0/). 


\section{INTRODUCTION}

The left atrial appendage (LAAp) is a common site for the formation of intracardiac thrombi in patients with atrial fibrillation. To reduce this risk, the administration of oral anticoagulants is the therapy of choice ${ }^{1}$. Nevertheless, some patients still remain at high risk of systemic embolism or do have a contraindication for anticoagulation therapy. In these patients, it is indicated to exclude or resect the LAAp2. This surgical or percutaneous procedure is effective in reducing systemic embolism ${ }^{3}$, but may disturb the normal physiological role of LAAp as a paracrine organ ${ }^{4}$. The natriuretic peptides (NPs) produced during LAAp stretching are not only used as biomarker to reflect the extent of heart failure (HF), but these hormones are also part of the biofeedback during HF when increased circulatory volume must be eliminated with the help of diuretic effect of these peptides ${ }^{5}$. Although NP may be produced in different parts of the body, atrial appendages are a major source of these peptides ${ }^{6}$. Furthermore, in situations of HF when there is a volume overload, the effect of the loss of atrial appendages as a source of NP to excrete sodium and water is still unclear ${ }^{7}$. In addition to its well-recognized function as paracrine organ, it has been postulated that atrial appendages serve as an anatomical area for additional distension, especially during acute fluid overload ${ }^{8}$.

This study was aimed to evaluate the role of atrial appendages during an acute fluid overload challenge by measuring the levels of several NP in an experimental swine model before and after the induction of ischemic HF. In addition, this study aimed to develop and validate an experimental model of LAAp resection that could be useful for future investigations in translational medicine.

\section{MATERIALS AND METHODS}

\section{Experimental subjects}

The study included 12 male Yorkshire pigs weighing $39-48 \mathrm{~kg}$ and 3 months of age. Swine were maintained for adaptation in the bioterium for a week, with periods of light/dark of $12 \mathrm{~h} / 12 \mathrm{~h}$ and food and water ad libitum. On the $1^{\text {st }}$ day of the study and $1 \mathrm{~h}$ after the first meal, $10 \mathrm{~mL}$ of peripheral blood were drained from all 12 swine to determine the basal NP serum levels (Fig. 1, Time 1A: pre-fluid challenge). On the same day, each pig received $3 \mathrm{~mL}$ of $0.9 \% \mathrm{NaCl}$ solution/100 g weight intravenously in $90 \mathrm{~min}$ as an acute fluid challenge. After this fluid challenge, $10 \mathrm{~mL}$ of peripheral blood were obtained for NP quantification (Fig. 1, Time 1B: post-fluid challenge).

\section{Surgical procedure}

Eight days after the first blood sampling, all pigs underwent a left anterior thoracotomy to induce ischemic $\mathrm{HF}$ by ligature of the circumflex (CX) artery branch. During thoracotomy, the animals were grouped as follows: Group 1, ligation of the CX branch was combined with the LAAp resection; Group 2, CX artery ligation was combined with the resection of both atrial appendages; and Group $0, C X$ artery ligation was performed and both atrial appendages were preserved. Twenty-four hours after surgery, serum troponin levels were measured to verify the extent of cardiac injury induced by myocardial infarction. One week after surgery, blood samples were obtained for NP quantification before and after a new acute fluid overload challenge with $3 \mathrm{~mL}$ of $0.9 \% \mathrm{NaCl}$ solution/100 g weight infused in 90 min (Fig. 1. Time 2A: pre-fluid challenge and Time $2 B$ : post-fluid challenge).

\section{Echocardiography}

Before and after cardiac surgery, transthoracic echocardiograms were obtained. Regional wall motion of the left ventricle (LV) was assessed and the LV ejection fraction (LVEF) was calculated ${ }^{9}$.

\section{Measurement of serum NP}

Levels of furin (sensitivity $0.1 \mathrm{ng} / \mathrm{ml}$; intra-assay variability $<15 \%$ ) and corin (sensitivity $0.1 \mathrm{ng} / \mathrm{ml}$; intraassay variability $<15 \%$ ) were measured by enzymelinked immunosorbent assay with commercially available kits (MyBiosource, San Diego, CA, USA). Levels of amino terminal pro-brain natriuretic peptide (NT-proBNP; sensitivity $6 \mathrm{pg} / \mathrm{ml}$; intra-assay variability $<10 \%$ ) and atrial NP (ANP; sensitivity $6 \mathrm{pg} / \mathrm{ml}$; intra-assay variability $<10 \%$ ) also were measured by enzyme-linked immunosorbent assay with commercially available kits (Cloud-Clone Corp., Houston, TX, USA). All samples were processed at 1 time, with the same batch and were performed in accordance with 
Figure 1. Flowchart including the study methodology. CX-Oc: circumflex artery occlusion; LAApR: left atrial appendage resection; LRAApR: resection of the left and right atrial appendages. Time 1A: before the fluid challenge; Time 1B: following the fluid challenge; Time 2A: before the fluid challenge, after CX-Oc; Time 2B: following the fluid challenge, after CX-Oc. The experimental protocol was performed using a total of 12 pigs, four animals in each surgical group. NP: natriuretic peptides.

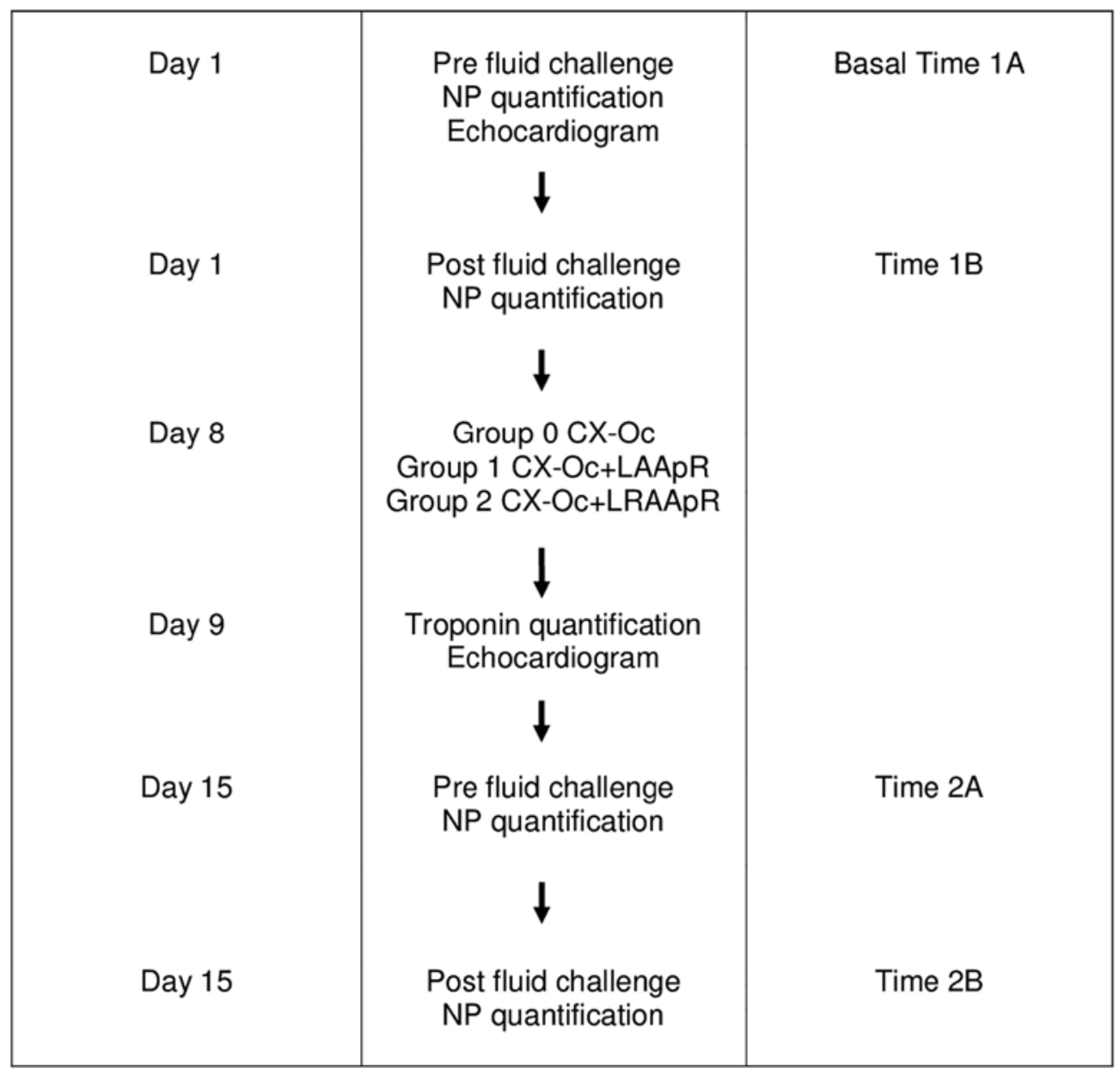

the manufacturer's instructions. All kits used are designed specifically for use in swine samples.

\section{Data analysis}

Data are expressed as median and interquartile range. Since there are no normal ranges for NP levels in swine, values of NP were normalized by dividing the concentration of each peptide measured in the different groups/times between the basal value (Time 1A; pre-fluid challenge). Levels of NP were compared between the study groups and the experimental interventions by a two-way ANOVA test (multiple comparison post-test by Tukey). $p \leq 0.05$ was set for statistical significance.
The study protocol was approved by the local ethics committee, protocol number 16-985.

\section{RESULTS}

Table 1 summarizes the serum values of troponins obtained $24 \mathrm{~h}$ after the CX artery occlusion, as well as the LVEF values calculated by transthoracic echocardiography at the baseline and after the thoracotomy. As can be observed, the CX artery ligation was consistently associated with myocardial infarction and its consequent damage in the ventricular function, that is, ischemic-induced HF was successfully achieved. 
Table 1. Troponin levels and echocardiographic parameters

\begin{tabular}{lccc}
\hline & $\begin{array}{c}\text { Preserved } \\
\text { appendages }\end{array}$ & $\begin{array}{c}\text { Left atrial } \\
\text { appendage } \\
\text { resected }\end{array}$ & $\begin{array}{c}\text { Left + right } \\
\text { atrial appendages } \\
\text { resected }\end{array}$ \\
\hline Weight, kg & $37.7 \pm 3.8$ & $50.0 \pm 0.8$ & $50.5 \pm 4.4$ \\
Troponin, $\mathrm{mg} / \mathrm{ml}$ & $24.5 \pm 6.9$ & $25.0 \pm 5.5$ & $16.0 \pm 7.2$ \\
LVEF, \% & $>70$ & $>70$ & $>70$ \\
- Time 1 & $44.7 \pm 5.6$ & $40.7 \pm 3.7$ & $43.7 \pm 2.2$ \\
- Time 2 & $47.6 \pm 8.5$ & $45.7 \pm 2.7$ & $48.7 \pm 1.7$ \\
- Time 3 & $49.6 \pm 8.0$ & $51.5 \pm 5.4$ & $51.7 \pm 3.8$ \\
\hline Time 4 & Tim & \\
\hline
\end{tabular}

Time 1, before surgery, with no fluid challenge. Time 2, before surgery, after fluid challenge. Time 3, after surgery, with no fluid challenge. Time 4 , after surgery, after fluid challenge. LVEF: left ventricular ejection fraction. All data are presented as mean \pm 1 standard deviation.

Before thoracotomy, there were no significant changes in the levels of furin before and after the challenge with fluid overload (Basal-1A and Basal-1B). However, after $\mathrm{HF}$ induction, furin levels became higher in Group 0-2A (atrial appendages preserved) compared to Group 1-2A (LAAp resected). The difference reached statistical significance when Group 0-2A (atrial appendages preserved) was compared with Group 2-2A (both appendages resected): 1.18 (1.031.84 ) versus $0.53(0.34-1.2)$, respectively (Fig. 2, Panel A). Administration of acute fluid overload after $\mathrm{HF}$ induction resulted in a significant increase of furin levels in Group 0-2B (2.07, 1.09-3.41) compared to the Basal-1B group (1.10, 0.92-1.33) (Fig. 2, Panel A). In contrast, furin levels decreased in Groups 1-2B and 2-2B (one or both appendages resected, respectively) compared to animals with both appendages preserved. The differences between furin levels after acute fluid overload during HF were statistically significant between Group 0-2B and Group 1-2B (2.07, $1.09-3.41$ vs. $0.86,0.60-1.08)$ and even more between Group 0-2B and Group 2-2B (2.07, 1.09-3.41 vs. $0.34,0.25-1.1$ ).

Before cardiac surgery, corin levels ( $1 \mathrm{~A})$ showed a significant increase following fluid overload (Basal-1A vs. Basal-1B) (Fig. 2, Panel B). It should be noted that the levels of corin increased even more after the acute fluid challenge when swine were in HF. Similar to furin levels, animals in $\mathrm{HF}$ with one or both appendages resected showed a decrease in corin levels, although no statistical significance was found (Fig. 2, Panel B).
The levels of NT-proBNP did not show significant differences between groups. However, as observed for the furin and corin levels, a tendency was observed to higher levels of NT-proBNP in animals with both appendages preserved (Fig. 2, Panel C).

Before cardiac surgery, ANP levels decreased after fluid overload (1 vs. 0.86, 0.57-1.26) (Fig. 2, Panel D). However, there was a significant increase in ANP levels in swine without both atrial appendages when HF was induced: Group 2-2A (2.55, 1.56-3.82) versus Basal-1A (1), versus Group 0-2A (1.03, 0.831.43), and versus Group 1-2A (1.01, 0.80-1.46). A similar significant increase in ANP levels occurred in $\mathrm{HF}$ animals with both appendages resected when an acute fluid challenge was administered: Group 2-2B $(2.21,1.29-3.66)$ versus Basal-1B $(0.87,0.69-1.10)$ and versus Group 1-2B (1.01, 0.80-1.46) (Fig. 2, Panel D).

\section{DISCUSSION}

Atrial appendages are closely involved in the production of NP, but the LAAp is often excluded during cardiac surgery or it is closed percutaneously for the prevention of cardiac embolism. The present study investigates, in a novel animal model, the impact of the exclusion of one or both atrial appendages in the production of different NP after an acute fluid overload in basal conditions and during ischemia-induced HF. Herein, we found that the resection of one, especially both atrial appendages, alters natriuretic 
Figure 2. Measurements of natriuretic peptides. The serum levels of furin, corin, NT-proBNP, and atrial natriuretic peptides are presented in panels (A-D), respectively. Values were normalized with respect to baseline values before the fluid overload challenge (Basal-1A).

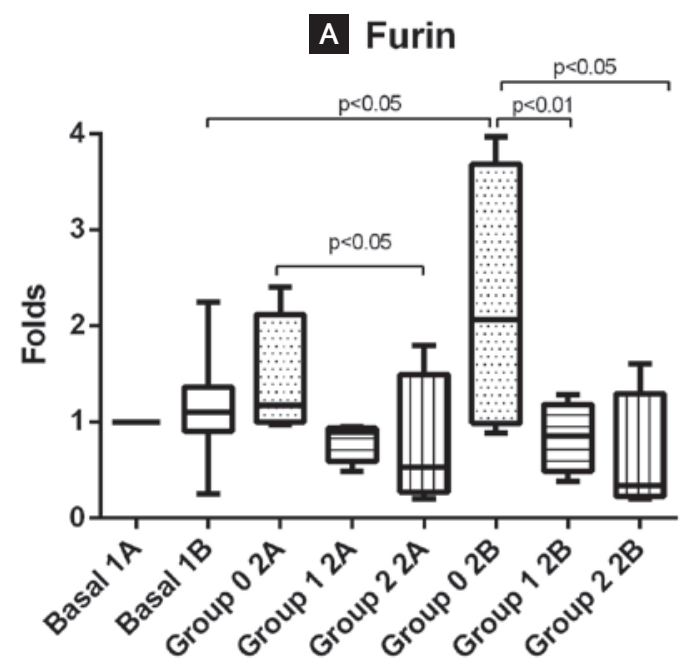

C ProBNP

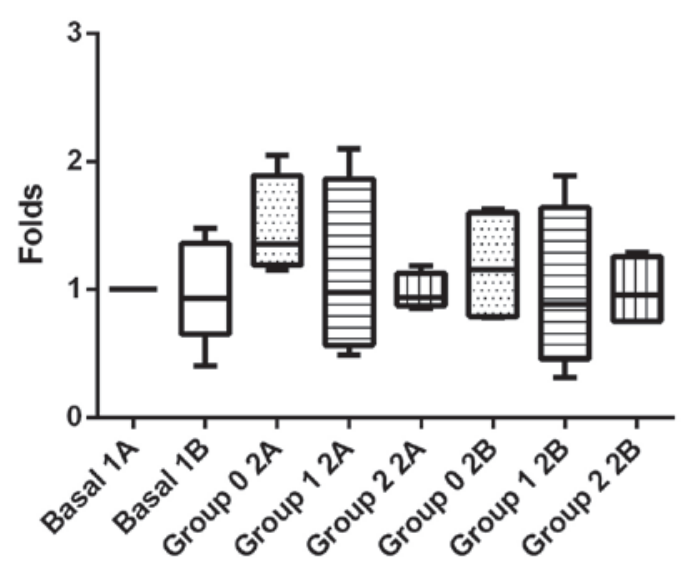

homeostasis by hindering the NP production. Therefore, this pilot study offers arguments for reconsidering the routine exclusion of the LAAp in patients with overt or subclinical HF.

Once HF is induced, furin levels become significantly higher in pigs with both appendages preserved compared to those with both appendages resected. When the acute fluid overload is administered during HF, the increase in serum furin becomes even higher among swine with preserved atrial appendages compared to animals with one or both appendages resected. A similar trend was observed for the corin levels,
B Corin
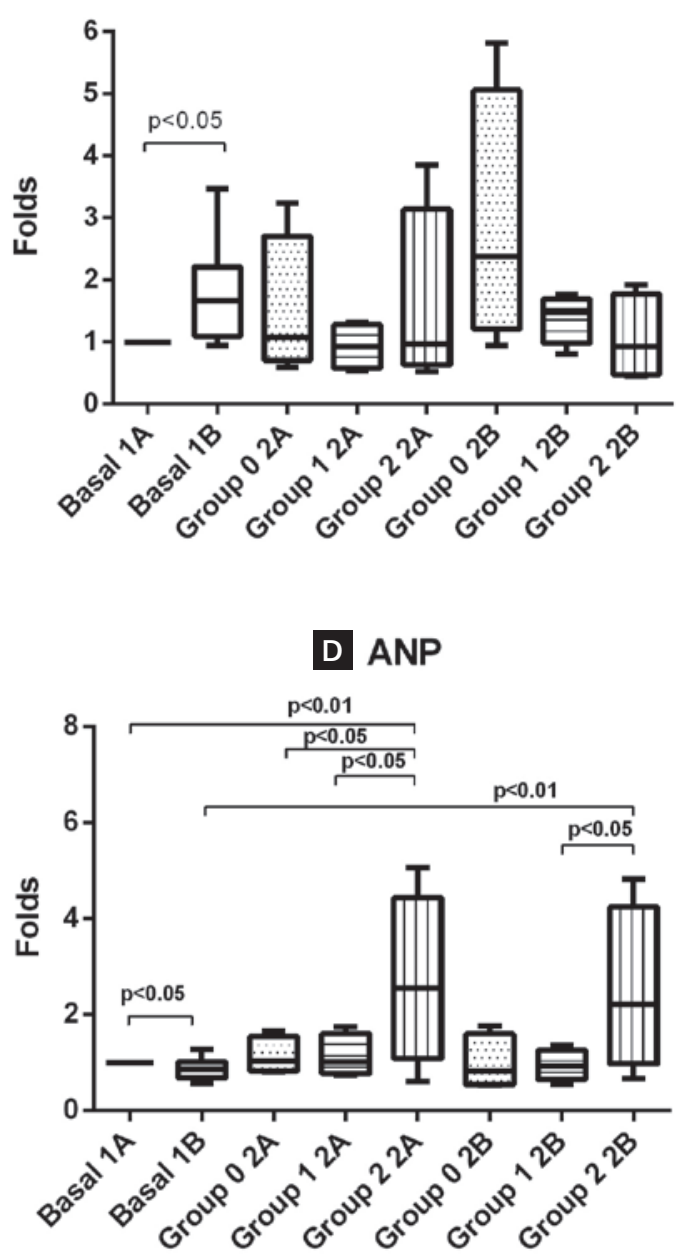

although this did not reach statistical significance. These findings and the decrease in furin and corin levels after an acute challenge with fluid during HF in those pigs with one or both appendages resected illustrate the importance of both appendages for the production of these NPs after an acute volume overload in the presence of HF. Previously ${ }^{10}$, Ichiki et al. demonstrated that furin mRNA expression is augmented in the atrium during the early stage of experimental (canine) HF and, conversely, corin mRNA and protein expressions are decreased with atrial remodeling. In a recent study ${ }^{11}$, Zhou et al. demonstrated the prognostic significance of corin levels in 
patients with chronic HF. When studying a prospective cohort that included 1148 patients with chronic $\mathrm{HF}$, the authors found that low corin levels are associated with an increase in the New York Heart Association functional class and with a decrease in the LVEF. In addition, multivariate analysis suggested that corin levels are an independent predictor of major adverse cardiac events, cardiovascular death, and rehospitalization due to HF. If atrial appendages are so important in the production of furin and corin, the exclusion of appendages could have a deleterious impact on natriuretic homeostasis, especially during acute HF.

After the induction of ischemic HF, NT-proBNP levels were not different in swine with both appendages preserved, neither before nor after acute fluid overload, compared to those with one or both appendages resected, suggesting that atrial appendages are not essential for the production of proBNP. This is in line with the notion that proBNP is a hormone secreted by cardiomyocytes in the ventricles rather than in the cardiac atria. Interestingly, ANP levels increased both before and after fluid overload in swine with HF, and both appendages resected (Group 2). This suggests that an important source of ANP is not within the atrial appendages, but in other parts such as in other regions of the atria and/or in the ventricles ${ }^{12}$, and even some extracardiac sources of ANP could be involved ${ }^{13,14}$. Alternatively, the rise in ANP levels during an acute fluid overload challenge in an HF condition could be interpreted as a possible compensation for the decrease in the production of furin and corin from the atrial appendages.

Under normal conditions, proBNP is cleaved by furin and corin and converted into the biologically active BNP and into the biologically non-active NT-proBNP15. Therefore, using NT-proBNP or BNP as a biomarker in HF patients in whom one or two atrial appendages have been excluded or resected may be clinically less useful. It could be one of the reasons why NT-proBNP-guided therapy in the Trial of Intensified versus Standard Medical Therapy in Elderly Patients with Congestive Heart Failure randomized trial was not superior to symptom-guided therapy to improve overall clinical outcomes in 499 patients with congestive HF followed up over an 18-month period ${ }^{16}$. Finally, Gommans et al. ${ }^{17}$ speculated that medication should be tailored for each patient with HF according to the different levels of NP. In this case, not only the different NP levels should be considered but also the lack of NP production due to the elimination of peptide sources such as the atrial appendages.

The impact of LAAp resection on natriuretic homeostasis and the long-term development of overt HF were recently studied in a small group of patients with atrial fibrillation ${ }^{18}$. In those patients undergoing LAAp resection, proANP levels increased after the procedure and did not return to baseline levels until 1 month after the surgery. Similar kinetics was observed for BNP levels. Clinical follow-up up to 2 years postoperatively showed no differences in the HF severity. Although interesting, these results do not allow us to evaluate the response of an amputated heart to an acute volume overload since these patients were under close clinical care including medications and restriction of water intake. In contrast, our experimental model allows us to evaluate the actual impact of the resection of one or both atrial appendages in different simulated clinical scenarios, such as an acute volume overload. In fact, this may be the main novelty of our study, the face and predictive validation of an experimental model of LAAp resection for future investigations in translational medicine. Our model meets the main validity and predictive criteria for an animal model useful in translational medicine as follows ${ }^{19}$ : (a) species, pigs are a species very close to humans, which make the pathophysiology of the disease similar to that observed in humans; (b) complexity, our in vivo model is much more complex than an isolated organ model, so it is likely that it may include almost all the relevant mechanisms in the pathophysiological process; (c) disease simulation, current model represents not only an attempt to simulate one or some disease symptoms but also recreates the ischemic heart disease and the impact of the resection of atrial appendages on natriuretic homeostasis; and (d) predictivity, this model allows to observe the effect of resecting atrial appendages as a graded response instead of a dichotomous response, both in basal conditions and after an acute fluid overload.

The results of the present study should be contrasted with its limitations. First, sample size in our study was limited, so the variation in infarct size in each animal and the subsequent differences in the HF expression could have influenced the data. Second, we do not know whether the exclusion of atrial appendages by a percutaneous procedure with closure device will give 
similar changes in the production of NP as when the appendages are completely resected, as has been done in our study. Finally, there are a number of NPs that were not assessed in our study.

The present study, based on a novel experimental model of subacute ventricular failure induced by ischemia, supports that atrial appendages are an important source of NP, and resection of atrial appendages drastically modifies the natriuretic mechanisms of cardiac homeostasis, especially after a fluid overload challenge. In addition, an increase in ANP levels in animals with both appendages resected was observed, suggesting the existence of intra- or/and extra-cardiac compensatory mechanisms, this finding has not been described previously. These results validate our experimental model for future translational investigations.

\section{ACKNOWLEDGMENTS}

This work was supported by the Instituto Nacional de Cardiología Ignacio Chávez (INCICH) and the Radboud University Nijmegen Medical Center, Geert Grooteplein, Nijmegen, Netherlands.

\section{REFERENCES}

1. Narumiya T, Sakamaki T, Sato Y, Kanmatsuse K. Relationship between left atrial appendage function and left atrial thrombus in patients with nonvalvular chronic atrial fibrillation and atrial flutter. Circ J. 2003;67:68-72.

2. Lewalter T, Ibrahim R, Albers B, Camm AJ. An update and current expert opinions on percutaneous left atrial appendage occlusion for stroke prevention in atrial fibrillation. Europace. 2013;15:652-6.

3. Reddy VY, Doshi SK, Kar S, Gibson DN, Price MJ, Huber K, et al. 5-Year outcomes after left atrial appendage closure: from the PREVAIL and PROTECT AF Trials. J Am Coll Cardiol. 2017; 70:2964-75.
4. Stewart JM, Dean R, Brown M, Diasparra D, Zeballos GA, Schustek $M$, et al. Bilateral atrial appendectomy abolishes increased plasma atrial natriuretic peptide release and blunts sodium and water excretion during volume loading in conscious dogs. Circ Res. 1992;70:724-32.

5. McMurray JJ, Packer M, Desai AS, Gong J, Lefkowitz MP, Rizkala AR, et al. Angiotensin-neprilysin inhibition versus enalapril in heart failure. N Engl J Med. 2014;371:993-1004

6. de Bold AJ. Atrial natriuretic factor: a hormone produced by the heart. Science. 1985;230:767-70.

7. Levin ER, Gardner DG, Samson WK. Natriuretic peptides. N Engl J Med. 1998;339:321-8.

8. Hoit BD, Shao Y, Tsai LM, Patel R, Gabel M, Walsh RA. Altered left atrial compliance after atrial appendectomy. Influence on left atrial and ventricular filling. Circ Res. 1993;72:167-75.

9. Hahn B, Bohn I, Strauer BE. Functional evaluation of left ventricular dynamics by use of 2-dimensional echocardiography: comparison with left ventriculography and assessment of normal 2-dimensional echocardiographical values. Z Kardiol. 1982; 71:445-51.

10. Ichiki T, Boerrigter G, Huntley BK, Sangaralingham SJ, McKie PM, Harty GJ, et al. Differential expression of the pro-natriuretic peptide convertases corin and furin in experimental heart failure and atrial fibrosis. Am J Physiol Regul Integr Comp Physiol. 2013;304:R102-9.

11. Zhou X, Chen JC, Liu Y, Yang H, Du K, Kong Y, et al. Plasma corin as a predictor of cardiovascular events in patients with chronic heart failure. JACC Heart Fail. 2016;4:664-9.

12. Kinnunen $P$, Vuolteenaho $O$, Ruskoaho $H$. Mechanisms of atrial and brain natriuretic peptide release from rat ventricular myocardium: effect of stretching. Endocrinology. 1993; 132:1961-70.

13. Poulos JE, Gower WR Jr, Sullebarger JT, Fontanet HL, Vesely DL. Congestive heart failure: increased cardiac and extracardiac atrial natriuretic peptide gene expression. Cardiovasc Res. 1996; 32:909-19.

14. Terán N, Rodríguez-Iturbe B, Parra G, Gutkowska J. Atrial natriuretic peptide levels in brain venous outflow during cardiopulmonary bypass in humans: evidence for extracardiac hormonal production. J Cardiothorac Vasc Anesth. 1991;5:343-7.

15. Ichiki T, Burnett JC Jr. Post-transcriptional modification of proBNP in heart failure: is glycosylation and circulating furin key for cardiovascular homeostasis? Eur Heart J. 2014;35:3001-3.

16. Pfisterer M, Buser P, Rickli H, Gutmann M, Erne P, Rickenbacher $P$, et al. BNP-guided vs symptom-guided heart failure therapy: the trial of intensified vs standard medical therapy in elderly patients with congestive heart failure (TIME-CHF) randomized trial. JAMA. 2009;301:383-92.

17. Gommans DH, Bayés-Genís A, van Kimmenade RR. Putting together the pieces of the natriuretic peptide puzzle. JACC Heart Fail. 2016;4:670-3.

18. Grieshaber P, Arneth B, Steinsberger F, Niemann B, Oswald I, Renz $\mathrm{H}$, et al. Influence of left atrial appendage amputation on natriuretic peptides-a randomized controlled trial. Thorac Cardiovasc Surg. 2019;10:1055-9.

19. Sams-Dodd F. Strategies to optimize the validity of disease models in the drug discovery process. Drug Discov Today. 2006; $11: 355-63$ 